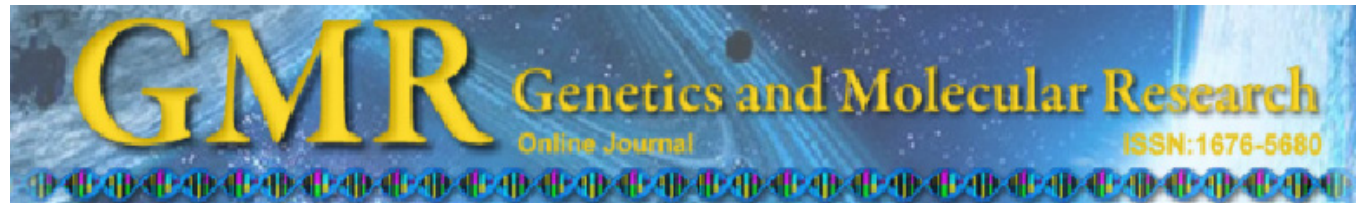

\title{
$\beta$-casein gene expression by in vitro cultured bovine mammary epithelial cells derived from developing mammary glands
}

\author{
P.S. Monzani, F.F. Bressan, L.G. Mesquita, J.R. Sangalli and \\ F.V. Meirelles
}

Faculdade de Zootecnia e Engenharia de Alimentos da Universidade de São Paulo, Pirassununga, SP, Brasil

Corresponding author: P.S. Monzani

E-mail: monzani.paulo@gmail.com

Genet. Mol. Res. 10 (2): 604-614 (2011)

Received November 3, 2010

Accepted January 24, 2011

Published April 12, 2011

DOI 10.4238/vol10-2gmr1034

\begin{abstract}
Epithelial cells from mammary gland tissue that are cultured in vitro are able to maintain specific functions of this gland, such as cellular differentiation and milk protein synthesis. These characteristics make these cells a useful model to study mammary gland physiology, development and differentiation; they can also be used for production of exogenous proteins of pharmaceutical interest. Bovine mammary epithelial cells were cultured in vitro after isolation from mammary gland tissue of animals at different stages of development. The cells were plated on Petri dishes and isolated from fibroblasts using saline/EDTA treatment, followed by trypsinization. Cells isolated on plastic were capable of differentiating into alveolus-like structures; however, only cells derived from non-pregnant and non-lactating animals expressed $\beta$-casein. Real-time qPCR and epifluorescence microscopy analyses revealed that alveolus-like structures were competent at expressing Emerald green fluorescent protein (EmGFP) driven by the $\beta$-casein promoter, independent of $\beta$-casein expression.
\end{abstract}

Key words: Mammary epithelial cell; In vitro culture; $\beta$-casein; GFP; Cellular differentiation 


\section{INTRODUCTION}

Mammary glands are formed by a system of ducts surrounded by glandular tissue; they are a useful system for organogenesis studies because of the cyclic processes of development and regression through successive cycles of gestation and lactation. The mechanisms controlling these processes have not been extensively studied, especially in bovines (Chotteau-Lelievre et al., 2003).

The study of the processes involved in in vivo lactation, such as control of milk synthesis and secretion, is hampered by the intrinsic characteristics of the system. Maintenance of homeostasis, for example, may interfere with treatments, and it contributes to the difficulty in predicting a pathway involved in milk secretion. In addition, the use of animals for such objectives raises ethical questions.

In vitro reproduction of mammary gland function has been performed by culturing mammary gland explants containing whole alveoli. Several groups have adopted this technique to study the action of hormones in the mammary gland, demonstrating the effect of leptin on the synthesis of milk proteins and lipids (Feuermann et al., 2004) and the influence of somatotrophin on $\beta$-casein mRNA levels (Yang et al., 2005). The great advantage of this culture strategy is the similarity in cellular composition and extracellular matrix to the in vivo tissue; therefore, the results of experimental manipulations closely represent what would occur in the natural environment. However, interpretation can be difficult because of the potential influence of the mammary gland tissue and the physiological condition of the animal that the tissue came from, including growth factors and hormones. In addition, difficulties in identifying the primary cell target of the factors added to the media, changes in each cell type within the tissue and the limited period of time in in vitro culture must be considered and can be important disadvantages to the explant system of culture (Rose and McConochie, 2006).

An alternative methodology to reproduce mammary gland biology is the culture of mammary gland epithelial cells (MECs), which are isolated and separated from the extracellular matrix to form a cell monolayer. MEC cultures from bovines were first developed by MacKenzie et al. $(1982,1985)$. They synthesize and secrete a large quantity of milk proteins, and the growth and differentiation stages are controlled by a variety of factors, including protein and steroid hormones, in addition to cell-cell and cell-substrate interactions (Mehta et al., 1980; Li et al., 1987; Schmidhauser et al., 1990). It has been reported that milk protein production by MECs (Suard et al., 1983; Lee et al., 1985; Li et al., 1987; Chen and Bissell, 1989; Rose et al., 2002; Zhao et al., 2010) and MEC differentiation into alveolus-like structures require culturing MECs on an extracellular matrix (Li et al., 1987; Rose et al., 2002). MEC culture on plastic commonly results in loss of specific functions within a few days (Larson, 1976), probably due to the loss of cell polarity (Rose and McConochie, 2006). Blum et al. (1989) also reported that cells cultured on plastic do not synthesize milk components and respond differently from in vivo MECs. One report, however, describes casein expression in bovine MEC (BMEC) cultured on plastic after induction of milk protein synthesis with lactogenic hormones (Ahn et al., 1995).

Mammary gland epithelial cells can become immortalized, either spontaneously or as a result of transfection by viral genes. Several lines of immortalized BMECs have been reported in the literature (Gibson et al., 1991; Huynh et al., 1991; Huynh and Pollak, 1995; Zavizion et al., 1996). These transformed lines do not express milk proteins or express very 
low levels of protein; this modest expression is commonly independent of some or all factors that control in vivo lactogenesis, such as hormones and extracellular matrix (Huynh et al., 1991).

In vitro MEC culture is a complex system in which various factors may interfere with milk protein synthesis, such as the condition of the animal when tissue is obtained (e.g., the animal may be lactating, pregnant, or dry), and the conditions and procedures for cell isolation and culture. Studies on BMEC culture can be used to determine the in vitro conditions for differentiation and expression of milk proteins.

Finally, BMEC culture may be a model system for the evaluation of cells and gene constructs to be used for the generation of transgenic animals that produce milk proteins of pharmacological interest (bioreactors). Using this system, transgenic BMECs may be isolated and evaluated regarding their capacity to express a protein of interest prior to their use as nucleus donors in somatic cell nuclear transfer. This methodology can contribute to improve the production of transgenic animals with adequate transgene expression.

\section{MATERIAL AND METHODS}

\section{Isolation and culture of bovine mammary epithelial cells}

Primary cells were isolated from the mammary glands of two Holstein cows (Bos taurus), one in late pregnancy and the other in lactation, and one Nelore cow (B. indicus), which was non-pregnant and non-lactating. These tissues were collected in slaughterhouses. For BMEC isolation, fragments of approximately $1 \mathrm{~cm}^{3}$ mammary gland tissue were removed and placed in Dulbecco's modified Eagle's medium (DMEM, Gibco) supplemented with an antibiotic and an antifungal agent ( $84 \mu \mathrm{g} / \mathrm{mL}$ amikacin and $50 \mu \mathrm{g} / \mathrm{mL}$ nystatin) and kept on ice for approximately $20 \mathrm{~min}$, which was the time taken for transport of the tissue to the laboratory. All further procedures were performed aseptically under laminar hoods. The tissue was washed in DMEM without serum and minced with sterile scissors and blades. Approximately $2 \mathrm{~g}$ minced tissue was placed in $10 \mathrm{~mL}$ trypsin (TryPLE Express, Gibco) and incubated for $3 \mathrm{~h}$ at $37^{\circ} \mathrm{C}$ with low agitation on a shaker. After incubation, digested tissue was centrifuged at $200 \mathrm{~g}$ for $2 \mathrm{~min}$ and suspended in $3 \mathrm{~mL}$ DMEM supplemented with $20 \%$ fetal bovine serum (FBS, Gibco), an antibiotic and a fungicide. Before cell plating, the flask was maintained in a vertical position for rapid decantation of larger pieces. Then, $60-\mathrm{mm}$ dishes were plated with $1 \mathrm{~mL}$ supernatant and $3 \mathrm{~mL}$ DMEM. In vitro cultures were incubated at $38.5^{\circ} \mathrm{C}$ with $5 \% \mathrm{CO}_{2}$. The cells were treated with saline/EDTA solution composed of $0.2 \mathrm{~g} / \mathrm{L}$ glucose, $0.2 \mathrm{~g} / \mathrm{L}$ EDTA, $8 \mathrm{~g} / \mathrm{L} \mathrm{NaCl}, 0.2 \mathrm{~g} / \mathrm{L} \mathrm{KCl}, 1.15 \mathrm{~g} / \mathrm{L} \mathrm{Na}_{2} \mathrm{HPO}_{4}$ and $0.2 \mathrm{~g} / \mathrm{L} \mathrm{KH}_{2} \mathrm{PO}_{4}$, at $\mathrm{pH} 7.2$, for $3 \mathrm{~min}$, at $38.5^{\circ} \mathrm{C}$ every 3 days to remove the majority of fibroblasts and thus allow growth of epithelial cell colonies. This procedure was performed until BMECs prevailed in culture. After epithelial cell colonies were growing, the remaining fibroblasts were removed by gentle trypsinization. Cells were trypsinized by incubation with $2 \mathrm{~mL}$ TryPLE Express for $3 \mathrm{~min}$ at $38.5^{\circ} \mathrm{C}$. Trypsinized cells were removed and the dishes were washed with DMEM free of FBS, and $2 \mathrm{~mL}$ TryPLE Express was added again and the cultures incubated for 15 to $18 \mathrm{~min}$ at $38.5^{\circ} \mathrm{C}$. BMECs collected after the second trypsinization were centrifuged and suspended in DMEM supplemented with $10 \% \mathrm{FBS}$ and amikacin and re-plated on 60-mm dishes. 


\section{Differentiation of epithelial cells into lobules and analysis of $\beta$-casein expression}

To evaluate the concentration of extracellular matrix necessary to promote BMEC differentiation into alveolus-like structures, six $35-\mathrm{mm}$ dishes were prepared with different concentrations of extracellular matrix (Geltrex, Invitrogen). Culture dishes were prepared with $500 \mu \mathrm{L}$ DMEM and the following protein concentrations of extracellular matrix: $0.55 \mathrm{mg} / \mathrm{mL}$, $1.10 \mathrm{mg} / \mathrm{mL}, 1.37 \mathrm{mg} / \mathrm{mL}, 2.19 \mathrm{mg} / \mathrm{mL}, 2.73 \mathrm{mg} / \mathrm{mL}, 5.47 \mathrm{mg} / \mathrm{mL}$ and $16 \mathrm{mg} / \mathrm{mL}$. BMECs derived from a pregnant Holstein cow were plated at $2.5 \times 10^{5}$ cells per dish and cultured in induction media containing DMEM, $5 \%$ FBS, $84 \mu \mathrm{g} / \mathrm{mL}$ amikacin, $5 \mu \mathrm{g} / \mathrm{mL}$ prolactin, $5 \mu \mathrm{g} /$ $\mathrm{mL}$ insulin and $5 \mu \mathrm{g} / \mathrm{mL}$ hydrocortisone. The differentiation process took approximately 30 days, and culture media were changed every three days. During the period of in vitro culture, cells were analyzed periodically to observe the development of alveolus-like structures.

To examine the expression of $\beta$-casein milk protein, two dishes were plated with 3 $\mathrm{mg} / \mathrm{mL}$ extracellular matrix protein for each isolated BMEC culture sample. The same procedures that applied to BMEC differentiation into alveolus-like structures were also applied for cell culture. The cells were cultured for 15 days and then trypsinized and collected. Total RNA from these cells was extracted using the Trizol reagent (Invitrogen), according to manufacturer instructions, and quantified with a spectrophotometer at $260 \mathrm{~nm}$ (NanoDrop 2000, Thermo Scientific). The extracted mRNA was used to generate cDNA by using $1 \mu \mathrm{g}$ DNase I-treated RNA and the Impron II kit (Promega) according to manufacturer instructions. The cDNA was evaluated for the relative expression of $\beta$-casein through quantitative polymerase chain reaction (qPCR) using the following primers: forward 5'-CCTCTTCCTCCAACTGT CATGTT-3', reverse 5'-AACAGGCAGGACTTTGGACTGA and probe 5'-FAM-CCTCCT CAGTCCGTGCTGTCCCTTT-TAMRA-3'. The primers for the endogenous bovine gene, glyceraldehyde 3-phosphate dehydrogenase (GAPDH), were as follows: forward 5'-AAGGC CATCACCATCTTCCA-3', reverse 5'-CCACTACATACTCAGCACCAGCAT-3' and probe 5'-VIC-AGCGAGATCCTGCCAACATCAAGTGGT-TAMRA-3'. The amplification reactions consisted of $2 \mathrm{X}$ Taqman master mix (Applied Biosystems), $0.9 \mu \mathrm{M}$ each primer and 0.25 $\mu \mathrm{M}$ Taqman probe in a final volume of $20 \mu \mathrm{L}$. The amplifications were performed at $50^{\circ} \mathrm{C}$ for $2 \mathrm{~min}, 95^{\circ} \mathrm{C}$ for $10 \mathrm{~min}$ and 50 cycles at $95^{\circ} \mathrm{C}$ for $15 \mathrm{~s}$ and $60^{\circ} \mathrm{C}$ for $1 \mathrm{~min}$. The differences in frequency of gene transcripts were calculated based on the standard curve method using five serial 1:1 dilutions of sample cDNA (Livak and Schmittgen, 2001).

\section{Lentiviral vector construction for EmGFP expression driven by the $\beta$-casein promoter}

The bovine $\beta$-casein upstream sequence was searched and retrieved from the bovine genome project (www.ncbi.nlm.nih.gov/), and the CSN2 region of chromosome 6 was selected (deposit code NW 001495211). This sequence was used to define the promoter regions in the 5' UTR of the $\beta$-casein gene. Primers were designed to amplify a fragment 5.335 $\mathrm{kbp}(\mathrm{P} \beta \mathrm{cas} 5)$ in length, which encompasses the 5' upstream region of the bovine $\beta$-casein gene and includes enhancers, the promoter region and the $5^{\prime}$ region of exon 1 of the bovine $\beta$-casein gene. Genomic DNA was extracted from the blood of a Holstein cow with the Wizard Genomic kit (Promega). Amplification of the P $\beta$ cas 5 fragment was accomplished in two steps. The first step consisted of amplification of a fragment of approximately $2.9 \mathrm{kbp}$ of a distal region of the bovine $\beta$-casein promoter ( $\mathrm{P} \beta$ cas-distal) using the forward primer, 
5'-ATCGATGTGGGGATAGACATG-3', which has the restriction site for ClaI, and the reverse primer, 5'-AAACCATGCAAATGATATCCTTAAG-3', which has the restriction site for AflII. In the second step, a fragment of approximately $2.4 \mathrm{kbp}$ containing the promoter region and the first nucleotides of the non-translated exon 1 (P $\beta$ cas-proximal) was amplified using the forward primer, 5'-CTTAAGGATATCATTTGCATGGT-3', which has a restriction site for AflII, and the reverse primer, 5'-GGATCCGTTAACTAGTCTCGTG-3', which has a restriction site for BamHI. Amplification of these regions was performed using recombinant Taq DNA polymerase (Invitrogen) following manufacturer instructions and approximately $200 \mathrm{ng}$ B. taurus genomic DNA. Reactions were cycled for $45 \mathrm{~s}$ at $94^{\circ} \mathrm{C}$ for denaturation, $30 \mathrm{~s}$ on a temperature gradient ranging from 50 to $58^{\circ} \mathrm{C}$ for annealing and 35 cycles for $1.5 \mathrm{~min}$ each at $72^{\circ} \mathrm{C}$ for synthesis.

The amplification products ( $\mathrm{P} \beta$ cas-distal and $\mathrm{P} \beta$ cas-proximal) were purified from a $1 \%$ agarose gel, recovered with the Wizard SV Gel kit and PCR Clean-Up System (Promega) and quantified at $260 \mathrm{~nm}$. Cloning of the amplification products was conducted using the pGEM cloning vector with the pGEM-T easy cloning kit (Promega). Ligation was done using the T4 DNA ligase enzyme at $4^{\circ} \mathrm{C}$ overnight. The product of ligation was transformed into Escherichia coli DH-5a cells, and selection of cells was performed with the chromogenic substrate, X-gal. Vectors from positive colonies were recovered with the Wizard Plus SV Minipreps kit (Promega). Positive clones were confirmed by restriction mapping with the appropriate restriction enzymes (Figure 1, lanes 1 and 2).

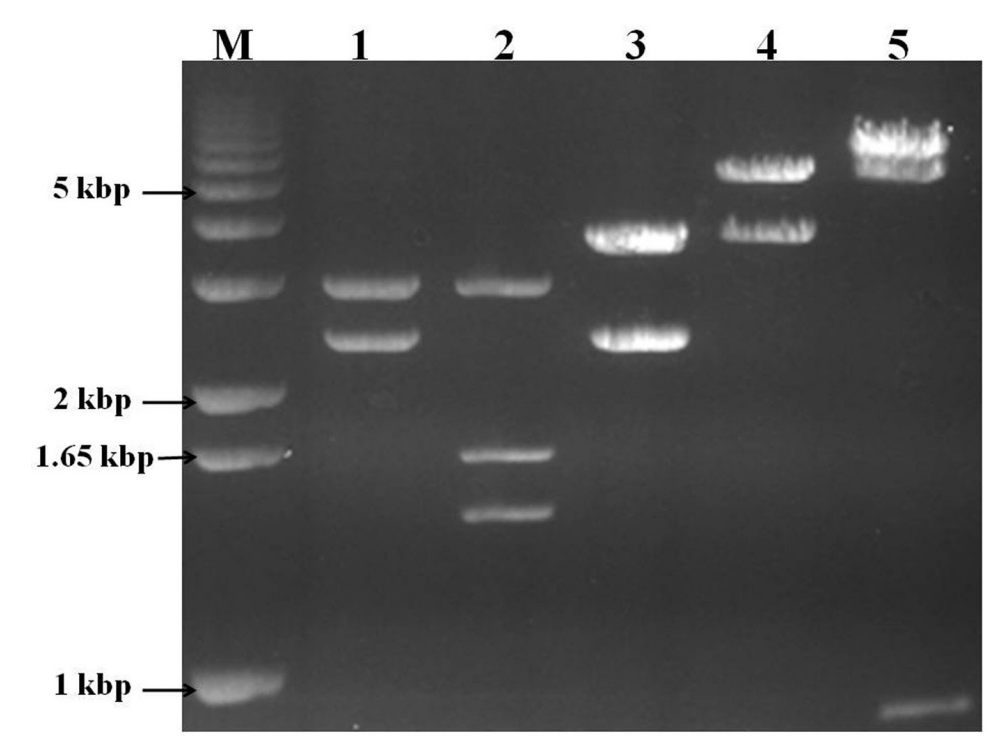

Figure 1. Steps of the lentiviral vector construction. Restriction mapping of the vector constructs. Lane $1=$ PGEM$\mathrm{P} \beta$ cas-proximal cleaved with the enzymes BamHI and Sall with the 3-kbp (pGEM) and 2.4-kbp (P $\beta$ cas-proximal) fragments; Lane 2 = pGEM-P $\beta$ cas-distal cleaved with the enzymes $A f I \mathrm{II}, A p a \mathrm{I}$ and $A h d \mathrm{I}$, with the 1.6- and 1.4-kbp fragments from pGEM ( $A$ hdI was used to cleave pGEM in two fragments for differentiation of the P $\beta$ cas-distal fragment) and the 2.9-kbp fragment (P $\beta$ cas-distal). Lane $3=\mathrm{pT} 7 \mathrm{blue} 3-\mathrm{P} \beta$ cas-proximal cleaved with the enzymes BamHI and SalI with the 3.8-kbp (pT7-blue3) and 2.4-kbp (Pßcas-proximal) fragments. Lane $4=$ pT7-blue3$\mathrm{P} \beta$ cas 5 cleaved with the enzymes BamHI and ApaI with the 3.8-kbp (pT7-blue3) and 5.3-kbp (P $\beta$ cas5) fragments. Lane $5=$ pLenti-P $\beta$ cas5-EmGFP cleaved with the enzymes ClaI, BamHI and XhoI with the 6.5-kbp (pLenti6.2GW/EmGFP), 5.3-kbp (Pßcas5) and 850-bp (EmGFP) fragments. 
The vectors, pGEM-P $\beta$ cas-distal and pGEM-P $\beta$ cas-proximal, were utilized to obtain the $\mathrm{P} \beta$ cas 5 fragment. The $\mathrm{P} \beta$ cas-distal and $\mathrm{P} \beta$ cas-proximal fragments were ligated to the pT7-blue3 vector (Novagen) using the following strategy: the proximal promoter region was removed from the pGEM-P $\beta$ cas-proximal vector using the restriction enzymes, BamHI and SalI, and ligated to the pT7-blue 3 vector that had been cleaved with the same enzymes. The resulting vector, pT7-blue3-P $\beta$ cas-proximal (Figure 1, lane 3), was cleaved with the restriction enzymes, AflI and ApaI. These same enzymes were used to remove the distal promoter region of the pGEM-P $\beta$ cas-distal vector. The insert, P $\beta$ cas-distal, and the vector, pT7-blue3-P $\beta$ casproximal, were ligated to obtain the pT7-blue3-P $\beta$ cas 5 vector. Verification of the constructs was made by restriction mapping using ApaI and BamHI (Figure 1, lane 4), and the product was partially sequenced.

The pLenti6.2-GW/EmGFP vector (Invitrogen), which has the reporter gene coding for Emerald green fluorescent protein (EmGFP), was cleaved with $C l a \mathrm{I}$ and $\mathrm{BamHI}$ to remove the $\mathrm{P}_{\mathrm{CMV}}$ promoter, and the $\mathrm{pT} 7$-blue3-P $\beta$ cas5 vector was cleaved with the same enzymes to isolate the $\mathrm{P} \beta$ cas 5 fragment. The products of cleavages were recovered and incubated with $\mathrm{T} 4$ DNA ligase (New England BioLabs) overnight at $4^{\circ} \mathrm{C}$, creating the pLenti-P $\beta$ cas5-EmGFP vector (Figure 1, lane 5).

\section{Lentiviral production, BMEC transduction and induction of EmGFP expression}

Lentiviral production was performed by lipofection of 293FT cells (Invitrogen) with the pLP1, pLP2 and pLP/VSV-G vectors (ViraPower packaging mix - Invitrogen) and the constructed vector, pLenti-P $\beta$ cas5-EmGFP. BMECs were cultured in $60-\mathrm{mm}$ dishes until 30\% confluence was reached, and cells were transduced by incubating $3 \mathrm{~mL}$ viral solution with $6 \mu \mathrm{g} / \mathrm{mL}$ hexadimethrine bromide (Polybrene, Sigma). After $24 \mathrm{~h}$, the viral solution was replaced by BMEC media without antibiotics and incubated for another $24 \mathrm{~h}$. Selection of transgenic cells was performed by adding $8 \mu \mathrm{g} / \mathrm{mL}$ blasticidin into the cultures for 20 days, and the medium was changed every 3 days. The blasticidin concentration was previously optimized using a killing assay that included $0,2,4,6,8$, and 10 $\mu \mathrm{g} / \mathrm{mL}$ concentrations of blasticidin in cultures of BMECs. Transgenic cells derived from a pregnant animal were cultured in induction media on extracellular matrix $(16 \mathrm{mg} / \mathrm{mL})$ for 60 days. The presence of EmGFP was analyzed by epifluorescence microscopy. After the induction period, alveolus-like structures were manually isolated from the monolayer using a stereomicroscope and automatic pipettes with $100 \mu \mathrm{L}$ tips. The remaining cells were trypsinized. Messenger RNA from both samples was extracted with Trizol reagent (Invitrogen) for cDNA generation. The relative expression of EmGFP and $\beta$-casein was determined by qPCR. The primers used for detection of EmGFP expression were, forward 5'-CCACATGAAGCAGCACGACTT-3', reverse 5'-GGTGCGCTCCTGGACGTA-3' and probe 5'-FAM-TTCAAGTCCGCCATGCCCGAA-TAMRA-3', as reported by Joshi et al. (2008), with replacement of one nucleotide in the forward primer. GAPDH expression was used as a control for endogenous gene expression. The presence of the transgene in BMEC cultures was analyzed by amplification of the EmGFP gene from the genomic DNA of these cells. 


\section{RESULTS AND DISCUSSION}

\section{Isolation and in vitro culture of bovine mammary epithelial cells}

The BMECs were isolated from animals at different stages of mammary gland development to check the capacity of these cells for in vitro culture. Subjective analysis revealed that tissue derived from a late pregnancy animal had a greater number of epithelial cell colonies on the dish when compared to fibroblasts. This finding is probably due to the advanced developmental stage of the mammary gland of this animal, with cells exhibiting increased mitotic activity, whereas lactating and non-lactating animals had a greater proportion of fibroblasts when compared to BMECs. Although only one animal was used at each developmental stage of the mammary gland, these results corroborate what is reported in the literature; in vitro culture of primary cells is hampered when the cells are derived from lactating animals when compared to cells derived from animals at developing stages (i.e., pregnant animals) (MacKenzie et al., 1985; McGrath, 1987; Rose et al., 2002).

The strategy of BMEC isolation using saline/EDTA treatment followed by gentle trypsinization proved to be efficient (Figure 2). The saline/EDTA treatment was able to remove the majority of fibroblasts, and after incubation with trypsin for $3 \mathrm{~min}$, the remaining fibroblasts were easily released. In contrast, BMECs are more adherent, and the release of these cells demanded approximately 15 min of incubation with trypsin. The differential sensitivity of fibroblasts and BMECs to EDTA and trypsin was recently described by Zhao et al. (2010). However, in some cases EDTA followed by trypsin treatment may compromise cell integrity. On a few occasions, newly developed BMEC colonies were removed from culture, while at other times, the cells lost adherence and the culture became unviable.

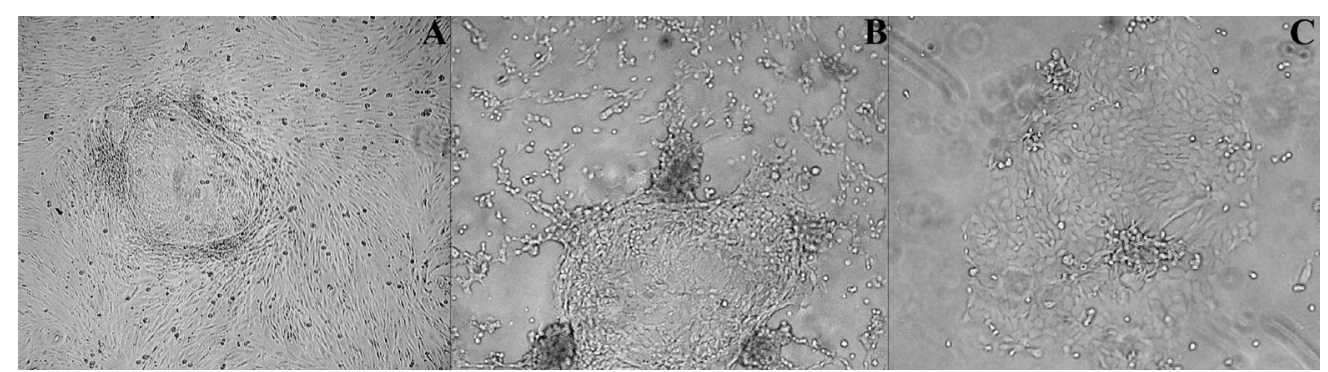

Figure 2. Strategy of bovine mammary epithelial cell (BMEC) isolation. A. Cell culture from mammary gland tissue shows fibroblasts and colony epithelial cells. B. Culture of mammary gland cells after treatment with saline/ EDTA solution. In this figure, it can be observed that the majority of fibroblast cells are removed. C. BMEC colony after treatment with trypsin, by which the remaining fibroblasts are removed.

\section{Differentiation of epithelial cells into alveolus-like structures and analysis of $\beta$-casein expression}

BMECs were first isolated and selected on plastic, and the culture was then transferred to extracellular matrix to determine whether isolation steps without extracellular matrix would interfere with cellular differentiation and expression of milk proteins. Previous studies have indicated that the use of extracellular matrix is essential for BMEC differentiation into alveo- 
lus-like structures (Li et al., 1987; Rose et al., 2002) and production of milk proteins (Suard et al., 1983; Lee et al., 1985; Li et al., 1987; Chen and Bissell, 1989; Rose et al., 2002; Zhao et al., 2010), and that BMEC culture on plastic prevents the synthesis of milk components (Blum et al., 1989) in a few days (Larson, 1976). Another group reported the expression of milk proteins when BMECs were cultured on plastic; however, they noted a gradual decrease in the synthesis of milk proteins upon repeated in vitro passage; thus, the ability to synthesize milk proteins almost completely disappeared after a long period of in vitro culture (Ahn et al., 1995).

To evaluate the differentiation capacity of cells initially cultured on plastic, BMECs derived from an animal in late gestation were cultured with different concentrations of extracellular matrix. Qualitative results obtained through observation of the cultures indicated that concentrations between 2.73 and $5.47 \mathrm{mg} / \mathrm{mL}$ efficiently differentiated the BMECs into alveolus-like structures after approximately nine days of culture. Development of these structures, however, was limited when compared with those obtained using a concentration of 16 $\mathrm{mg} / \mathrm{mL}$. Concentrations lower than $2.73 \mathrm{mg} / \mathrm{mL}$ showed lower differentiation efficiency (data not shown). The cells cultured with pure extracellular matrix (without dilution, $16 \mathrm{mg} / \mathrm{mL}$ ) showed the best differentiation result; however, cells cultured in this condition were not able to form a monolayer and differentiate, at least initially. After plating, adherent cells formed a cluster of cells and secreted a large quantity of extracellular material. After approximately 15 days in culture, the formation of a cell monolayer was observed, and alveolus-like structures were observed after approximately 30 days. After this experiment, BMECs derived from a pregnant animal were cultured with extracellular matrix at a concentration of $5 \mathrm{mg} / \mathrm{mL}$, and alveolus-like structures were obtained after approximately nine days (Figure 3). These results show that cells initially isolated on plastic are still able to differentiate.

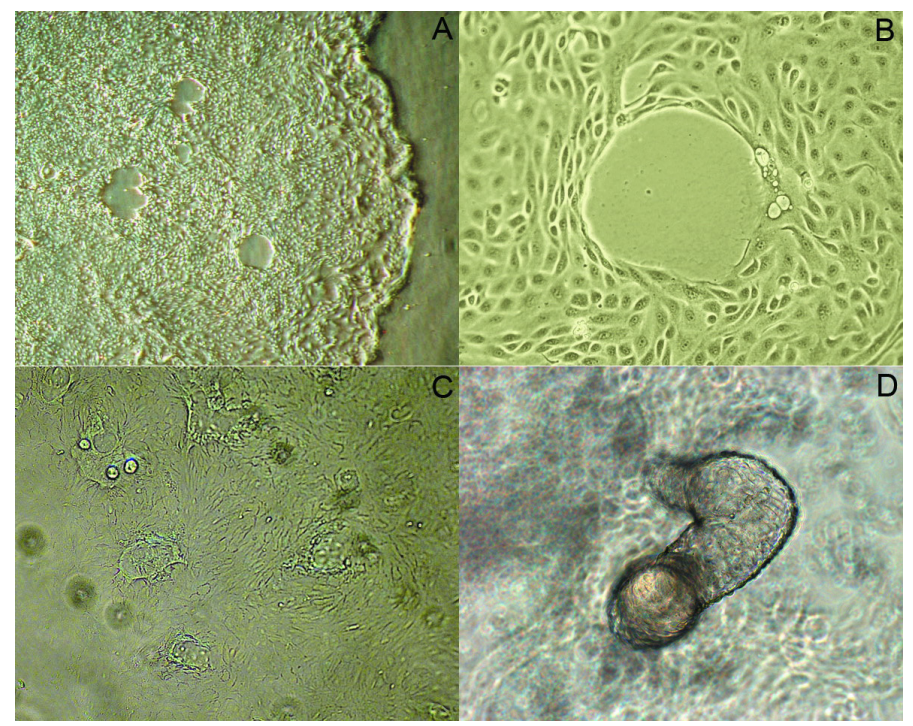

Figure 3. Different stages of bovine mammary epithelial cell differentiation. A. The lumen-like structure formed around the cell, $10 \times 4 ; \mathbf{B}$. The lumen-like structure in detail, $10 \times 10$; C. The initial stage when the lobular-like structures form, around nine days in culture, $10 \times 10$. D. The lobular-like structure at around 60 days of culture on undiluted extracellular matrix, 10 x 4. 
To evaluate the expression of milk proteins, cells cultured in induction medium and differentiated into alveolus-like structures were analyzed for $\beta$-casein mRNA. In this experiment, cells derived from pregnant animals or lactating animals (B. taurus) were not capable of expressing $\beta$-casein, whereas cells derived from a non-pregnant and non-lactating cow $(B$. indicus) expressed $\beta$-casein (Figure 4). Even when initially cultured on plastic, these cells are capable of expressing milk proteins, as previously reported (Ahn et al., 1995).

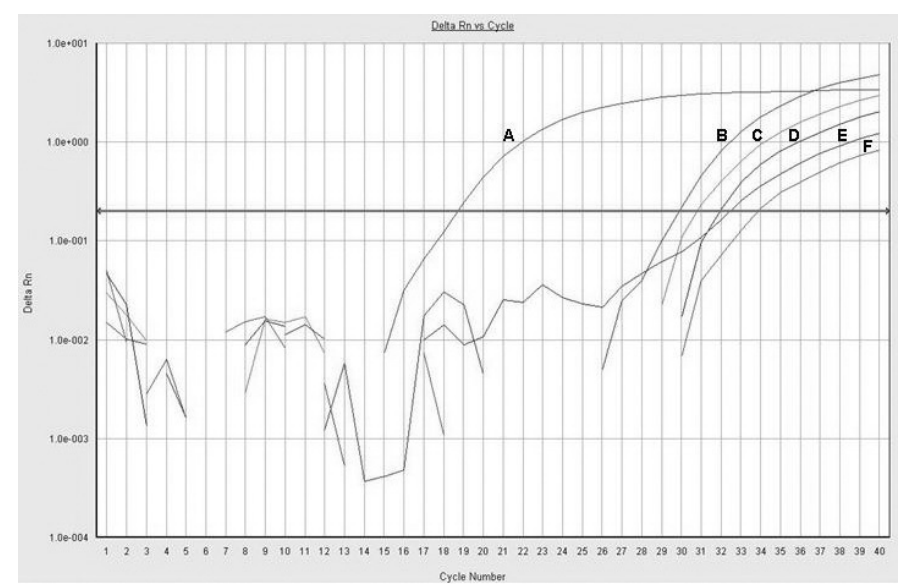

Figure 4. Analysis of $\beta$-casein expression by qPCR in samples from animals at different stages of mammary gland development. $\beta$-casein expression can be observed only in non-pregnant and non-lactating animals (Bos indicus). A. GAPDH expression. B. to F. Expression of the $\beta$-casein with serial dilution of the $B$. indicus cDNA cells.

\section{EmGFP expression driven by the $\beta$-casein promoter}

The results of the amplification of fragments from the two promoter regions and the construction of the vector expressing the reporter gene are summarized in Figure 1.

$\beta$-casein production has been proposed to occur preferentially in alveolus-like structures; it is secreted directly into the lumen (Schmidhauser et al., 1990). To determine the localization of $\beta$-casein expression in BMEC cultures, transgenic cells expressing the EmGFP gene driven by the $\beta$-casein promoter were generated. The relative quantification of EmGFP expression was analyzed in alveolus-like structures and the cell monolayer. Lobular structures exhibited EmGFP-derived fluorescence, while the monolayer did not exhibit fluorescence (Figure 5).

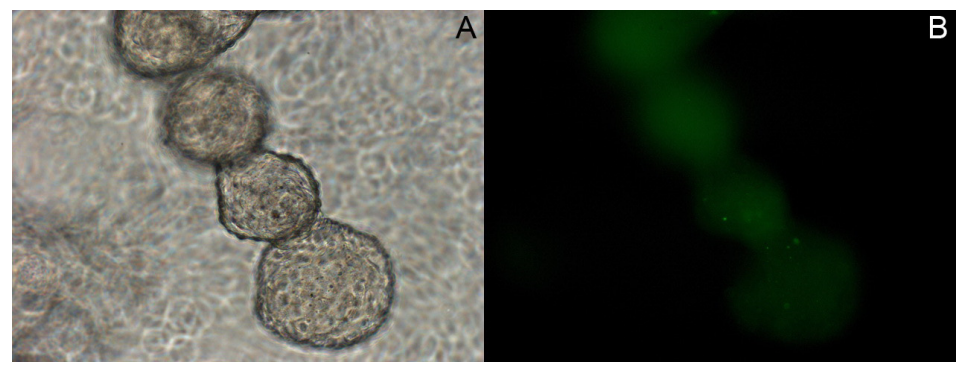

Figure 5. Analysis of EmGFP expression driven by the $\beta$-casein promoter using epifluorescence microscopy. A. Bright field. B. Epifluorescence. This figure shows that EmGFP expression occurs preferentially in the alveolar-like cells. 
This result indicates that $\beta$-casein is preferentially expressed in lobular structures, which is in agreement with a study suggesting that such structures present a greater capacity for $\beta$-casein expression and secretion of milk proteins into the lumen (Schmidhauser et al., 1990). Analysis of relative expression showed that the lobular structures were capable of expressing the reporter gene at a rate 5-fold higher than the monolayer (Figure 6). Because these structures were manually isolated, contamination of lobules with remaining cells from the monolayer is possible. Therefore, it is inferred that expression of the reporter gene in the lobular structures may be even higher than what was initially estimated.

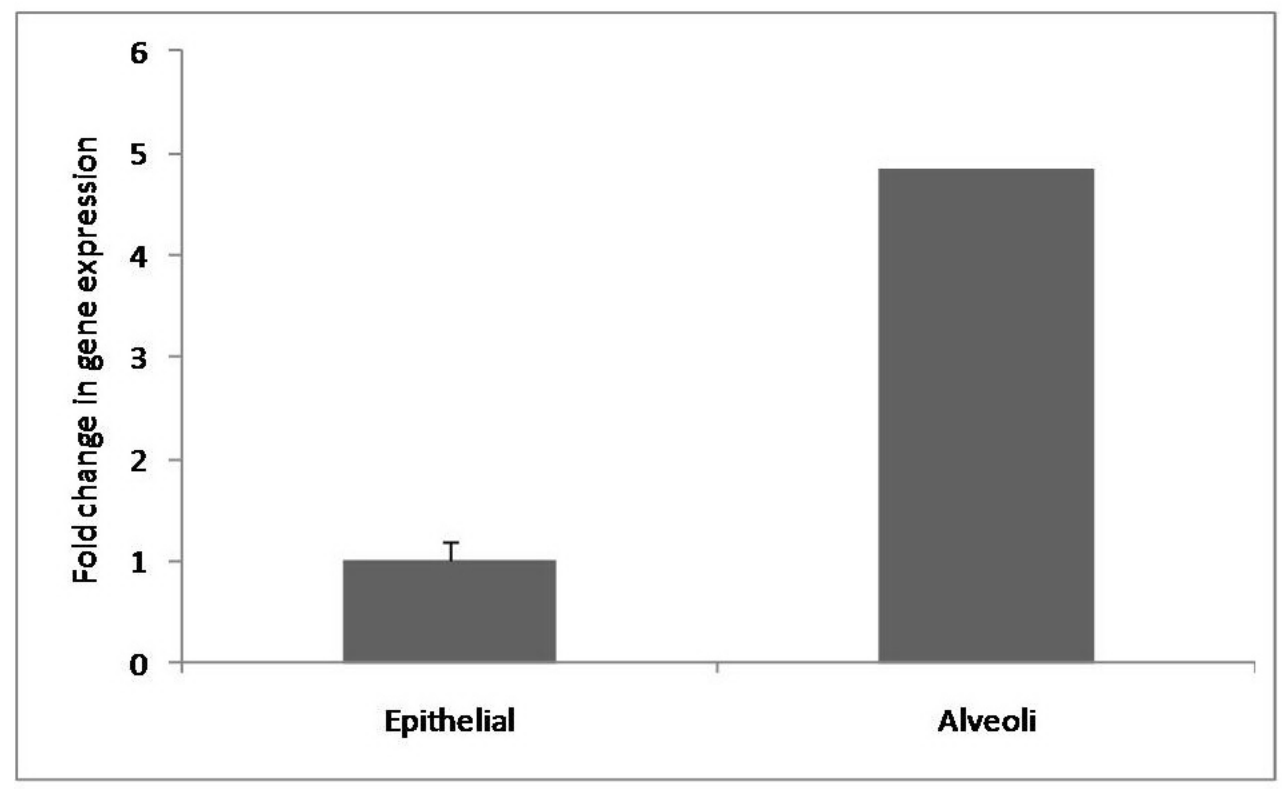

Figure 6. Analysis of the relative EmGFP expression driven by the $\beta$-casein promoter in the cell monolayer and alveolar-like structures using qPCR. The plot represents the arithmetic mean from samples of the different cell types. The alveolar-like structures show approximately 5 -fold higher expression than monolayer cells.

The BMECs derived from a pregnant cow lost their capacity to express $\beta$-casein, as shown by PCR. This lack of expression was not observed for reporter gene expression driven by the $\beta$-casein promoter. This suggests that, if the mechanism regulating endogenous gene silencing mediated by the plastic culture relies on the $\beta$-casein promoter, the gene must also be regulated by other regulatory regions not present in our construct or somehow dependent on the location of the promoter within the genome. Another hypothesis is that the $\beta$-casein gene silencing occurred before genetic modification, at the time when cells were cultured on plastic for the initial isolation; therefore, this silencing had no effect on the modification.

In conclusion, in vitro-cultured BMECs, even when not capable of expressing milk proteins, may be used as an efficient system to determine the capacity of these cells to express recombinant proteins. This system, therefore, is an important evaluation step for the development of bioreactors that produce proteins of interest in animal milk. 


\title{
ACKNOWLEDGMENTS
}

\author{
The authors thank FAPESP for financial support.
}

\section{REFERENCES}

Ahn JY, Aoki N, Adachi T, Mizuno Y, et al. (1995). Isolation and culture of bovine mammary epithelial cells and establishment of gene transfection conditions in the cells. Biosci. Biotechnol. Biochem. 59: 59-64.

Blum JL, Zeigler ME and Wicha MS (1989). Regulation of mammary differentiation by the extracellular matrix. Environ. Health Perspect. 80: 71-83.

Chen LH and Bissell MJ (1989). A novel regulatory mechanism for whey acidic protein gene expression. Cell. Regul. 1: 45-54.

Chotteau-Lelievre A, Montesano R, Soriano J, Soulie P, et al. (2003). PEA3 transcription factors are expressed in tissues undergoing branching morphogenesis and promote formation of duct-like structures by mammary epithelial cells in vitro. Dev. Biol. 259: 241-257.

Feuermann Y, Mabjeesh SJ and Shamay A (2004). Leptin affects prolactin action on milk protein and fat synthesis in the bovine mammary gland. J. Dairy Sci. 87: 2941-2946.

Gibson CA, Vega JR, Baumrucker CR, Oakley CS, et al. (1991). Establishment and characterization of bovine mammary epithelial cell lines. In Vitro Cell. Dev. Biol. 27A: 585-594.

Huynh H and Pollak M (1995). HH2A, an immortalized bovine mammary epithelial cell line, expresses the gene encoding mammary derived growth inhibitor (MDGI). In Vitro Cell. Dev. Biol. Anim. 31: 25-29.

Huynh HT, Robitaille G and Turner JD (1991). Establishment of bovine mammary epithelial cells (MAC-T): an in vitro model for bovine lactation. Exp. Cell. Res. 197: 191-199.

Joshi M, Keith PH, Haisch C and Verbanac K (2008). Real-time PCR to determine transgene copy number and to quantitate the biolocalization of adoptively transferred cells from EGFP-transgenic mice. Biotechniques 45: 247-258.

Larson BL (1976). Comparative production of beta-lactoglobulin and orotic acid with lactose in bovine mammary cell cultures: effects of cell density and constituent inhibition. J. Dairy Sci. 59: 1881-1889.

Lee EY, Lee WH, Kaetzel CS, Parry G, et al. (1985). Interaction of mouse mammary epithelial cells with collagen substrata: regulation of casein gene expression and secretion. Proc. Natl. Acad. Sci. U. S. A. 82: 1419-1423.

Li ML, Aggeler J, Farson DA, Hatier C, et al. (1987). Influence of a reconstituted basement membrane and its components on casein gene expression and secretion in mouse mammary epithelial cells. Proc. Natl. Acad. Sci. U. S. A. 84: 136-140.

Livak KJ and Schmittgen TD (2001). Analysis of relative gene expression data using real-time quantitative PCR and the 2(-Delta Delta C(T)) Method. Methods 25: 402-408.

MacKenzie DD, Forsyth IA, Brooker BE and Turvey A (1982). Culture of bovine mammary epithelial cells on collagen gels. Tissue Cell 14: 231-241.

MacKenzie DD, Brooker BE and Forsyth I (1985). Ultrastructural features of bovine mammary epithelial cells grown on collagen gels. Tissue Cell 17: 39-51.

McGrath MF (1987). A novel system for mammary epithelial cell culture. J. Dairy Sci. 70: 1967-1980.

Mehta NM, Ganguly N, Ganguly R and Banerjee MR (1980). Hormonal modulation of the casein gene expression in a mammogenesis-lactogenesis culture model of the whole mammary gland of the mouse. J. Biol. Chem. 255: 4430-4434.

Rose MT and McConochie H (2006). The long road to a representative in vitro model of bovine lactation. JIFS 3: 67-72.

Rose MT, Aso H, Yonekura S, Komatsu T, et al. (2002). In vitro differentiation of a cloned bovine mammary epithelial cell. J. Dairy Res. 69: 345-355.

Schmidhauser C, Bissell MJ, Myers CA and Casperson GF (1990). Extracellular matrix and hormones transcriptionally regulate bovine beta-casein 5' sequences in stably transfected mouse mammary cells. Proc. Natl. Acad. Sci. U. S. A. 87: 9118-9122.

Suard YM, Haeuptle MT, Farinon E and Kraehenbuhl JP (1983). Cell proliferation and milk protein gene expression in rabbit mammary cell cultures. J. Cell. Biol. 96: 1435-1442.

Yang J, Zhao B, Baracos VE and Kennelly JJ (2005). Effects of bovine somatotropin on beta-casein mRNA levels in mammary tissue of lactating cows. J. Dairy Sci. 88: 2806-2812.

Zavizion B, van Duffelen M, Schaeffer W and Politis I (1996). Establishment and characterization of a bovine mammary epithelial cell line with unique properties. In Vitro Cell. Dev. Biol. Anim. 32: 138-148.

Zhao K, Liu HY, Zhou MM and Liu JX (2010). Establishment and characterization of a lactating bovine mammary epithelial cell model for the study of milk synthesis. Cell. Biol. Int. 34: 717-721. 